\title{
İslam Tarihinde Vakıf Kültürü Üzerine Bir İnceleme
}

Hakkı Yapıcı 1

\begin{abstract}
Özet
İslam tarihinde vakıf müesseseleri, insanların ve diğer canlıların yararına olan muhtelif hizmetleri ifa etmek için tesis edilmişlerdir. İnsanlığa karşılıksız hayır yapmanın, yardım etmenin, uzlaşmanın, varlıklı olandan muhtaç olana kaynak tahsis etmenin en güzel örneğini sergilemektedir. Vakıflar, bütün bunların gönüllülük esasına dayanan tarzda yerine getirildiği bir kültür ve sosyal güvenlik kurumu olmuşlardır. Vakıf geleneğinin devamını sağlamak maksadıyla bu tesislerin giderlerini karşılayan akar nitelikli ticarî ve ziraî işletmeler tahsis ederek sağlıklı bir toplum hayatının devamına hizmet etmişlerdir. Aynı zamanda vakıf müesseseleri, İslâm memleketlerinin, dolayısıyla Osmanlı'nın sosyal ve iktisâdî hayatının gelişmesinde ehemmiyetli bir rol oynamıştır.
\end{abstract}

Anahtar Kelimeler: Vakıf, Hayır, İslam, Toplum, Kültür.

\section{A Research on Waqf Culture in İslamic History}

\begin{abstract}
Within Islamic history, waqfs have been established in order to fulfill various services to the benefit of both humans and other living beings. These waqfs set the best example of doing voluntary charity work for humanity without demanding anything, helping people, contributing to social reconciliation, as well as ensuring a flow of funds from the rich to the poor. They have been cultural and social security institutions where aforementioned services have been performed on a voluntary basis. In order to ensure the continuance of the tradition of waqfs, these waqfs have been provided with commercial and agricultural enterprises having the quality of real property to meet their expenses, as a result of which these waqfs have served the continuance of a healthy social life. Additionally, they have played a significant role in the development of social and economic life of the Islamic countries, including that of the Ottoman Empire.
\end{abstract}

Key Words: Waqf, Good, Islam, Community, Culture.

\footnotetext{
${ }^{1}$ Dr., Erzurum Yakutiye Şair Nefi Ortaokulu , hyapici25@hotmail.com
} 


\section{GíRiş}

\section{Vakfın Tanımı}

Vakf kelimesi Arapça bir isim olup, "durdurma, alıkoyma, ayırma, bağlama, bir malı veya mülkü-satılmamak kaydıyla- bir hayır işine bağışlama, bırakma" anlamlarına gelmektedir (Akgündüz, 1988: 29; Develioğlu 1995: 1134). Bilhassa hukuki anlama yakın manadaki "vakıf" mastarının çoğulu, "evkaf" ve "vukûf" şeklinde telaffuz edilmektedir. İslâm hukukunda ise, bir mülkün bütün faydasını karşılık beklemeden insanların yararına bırakarak, kıyamete kadar başka birinin mülküne geçmeyecek şekilde kullanımının sürekliliğini temin etmektir (Akbulut, 2007: 64).

\section{Vâkıfın Dayandığı Ana Kaynaklar}

\section{a. Kuran-ı Kerim}

Kuran-1 Kerim'de doğrudan doğruya "vakıf" terimi yer almamaktadır. Ancak vakıf konusunu içeren hayrî ve sosyal hizmetler birçok ayetlerle teşvik edilmiştir. Vakıf geleneğinin olgunlaşmasında Kuran-1 Kerim'de" iyilik yapmak, sadaka vermek, infak etmek ve ihsanda bulunmak" gibi yardımı teşvik eden pek çok ayet bulunmaktadır (Öztürk, 1983: 40). Konuyla ilgili şu ayetleri verebiliriz:

“İbadet, yeri olarak yeryüzünde yapılan ilk bina Mekke'deki Kâbe'dir; o pek feyizlidir, insanlar için hidayet rehberidir. Orada apaçık alâmetler ve deliller, Ibrahim 'in makamı vardır..."2

"Sevdiğiniz şeylerden sadaka vermedikçe cennete giremezsiniz. Allah yolunda her ne harcarsanız muhakkak Allah onu bilendir."”

"Hayır işleyiniz ki kurtulabilesiniz."

"Iyilik yapmak ve fenalıktan sakınmak hususunda birbirinizle yardımlaşın",

Kuran-1 Kerim'de vakıftan terim olarak ayrıca söz açılmaması buna lüzum duyulmamasıdır. Çünkü İslâm, vakıfların göreceği işleri esasında devlete bir görev olarak vermiştir. Ayrıca yardımlaşmanın bütün kurallarını saymış ve fertleri de, devlete verilen ödevin yerine getirilmesinde, devlete yardımc1 olmaya, insanî ve diyan̂̂ $\hat{}^{6}$ öğütlerle teşvik etmiştir. "Vakıf" kelimesinin terim

\footnotetext{
${ }^{2}$ Kur'an, Âl-i İmrân, 3/96-97.

${ }^{3}$ Kur'an, Âl-i İmrân, 92.

${ }^{4}$ Kur'an,el-hac, 77.

${ }^{5}$ Kur'an, el- maide, 2.

6 "Diyanî"; Diyanetle ilgili şeyler...
} 
olarak Kur'anda geçmemesi nedeniyle vakıf kurumunun doğrudan doğruya bu ana kaynağa dayandırılmasının kolay olmadığını iddia edenler varsa da; kurumun tarihi gelişimi ve tatbikatına bakarak kıyas ve istidlâl yoluyla Kuran-1 Kerime dayandırılabileceği; hatta vakıfların kendisine gaye olarak seçtiği çalışma sahalarının birçok ayetlerle izah edilmiş bulunduğunu ve insanların bu konulara israrla teşvik edildiğini rahatlıkla söyleyebiliriz (Öztürk, 1983: 41-44).

\section{a. Hadis ve Rivayetler}

Vakıf bırakmayı özendiren ve yaygınlaşmasına vesile olan $\mathrm{Hz}$. Peygamberin bu konu ile alakalı pek çok Hadis-i Şerifi de bulunmaktadır. Ebû Hüreyre (R.A)'den rivayet edilen bir Hadis-i Şerifte Hz. Peygamber şöyle buyurmaktadır: "Insanoğlu öldüğü zaman bütün amelleri kesilir. Ancak, devam eden sadaka (sadaka-i câriye), faydalanılan ilim ve kendisine duâ eden sâlih bir evlad birakanlarınki kesilmez." 7 Bu hadisten de açıkça anlaşılacağı gibi "sadaka-i cariye" ifadesi hayır işi kabul edeceğimiz vakıf konusuna vurgu yapılmaktadır. $\mathrm{Bu}$ müjdeye mazhar olmak isteyen Müslümanlar güçleri ölçüsünde hayır yolunda adeta birbirleriyle yarışmışlardır. Vakıf konusu Müslümanlar için gerçek bir cömertlik aynı zamanda karşılıksız verme noktasında büyük bir imtihan aracı olmuştur. Böylece dünyada iken kendi nefislerini de terbiye etmeye muvaffak olmuşlardır.

Kur'an ayetlerine nazaran hadiste vakıf kurumu daha geniş yer almıştır. Mescid yapmayı, su akıtmayı, yolda kalmışları gözetmeyi, yolcular için han ve kervansaray yapmayı, hayatında ve sıhhatli halinde malından sadaka ayırmayı ögütleyen ve bu gibi davranışları öven hadisler çoktur. Bunların hepsinde de topluma sağladığı fayda sürekli olan, sadaka-i câriye' den söz edilmektedir ki bu vakıftan başka bir şey değildir. Fıkıh ve hadis kitaplarının konuya ilişkin bölümleri ile müstakil olarak "vakıf" hakkında yazılan eserlerle, bizzat Hz. Peygamberin vakıf yaptığından bahsedilmektedir. Sahîh-i Buhârî'den nakledilen bir hadîs, bir arazinin, Resulullah tarafından, menfaati yolculara ait olmak üzere vakfedildiğini göstermektedir. Amr bin Hâris'in rivayet ettiği hadis şöyledir: "Resûl-i Ekrem (s.a) vefat ettiği vakit, arkasında ne gümüş, ne köle, ne cariye, ne de başka bir şey bırakmadı. Yalnız, binmekte olduğu beyaz bir katır ile silahını ve birde yolculara "vakfettiği” Fedek ve Hayber'deki hurmalı̆̆ bıraktı (Öztürk, 1983: 44-45).

\footnotetext{
${ }^{7}$ Tirmizî, Ahkâm, 36; Ebû Dâvud, Vesâyâ, 14; Müslim, Vasiyye, 14.
} 
Hz. Peygamber'in (s.a.) huzurunda, Medinede'ki "semg" adıyla anılan mülkünü vakfetmek suretiyle Hz. Ömer ashap arasında ilk vakıf yapan sahabi olmuştur. İbni Ömer'in (r.a.) rivayet ettiği bir hadisten öğrendiğimize göre Hz. Ömer, vakfetmek istediği Hayber'deki öz malı hurmalığı hakkında, Peygamber'e (s.a.) danışmış $O$ da "istersen aslını habs yani vakfedip, hâsılatını tasadduk et" buyurmuştur. Hz. Ömer de o yerin aslını satılmaz, satın alınmaz, bağışlanmaz ve miras yoluyla intikâl etmez şekilde vakfedip; gelirini Allah yolunda gaza eden mücahitlere, esâretten kurtulmak isteyen kölelere, yolculara, misafirler ve muhtaç akrabaya tasadduk etmiştir (Öztürk, 1983: 46-47).

.Hz. Ömer, Hz. Osman, Ebu Talha ve Sa'd (r.a), Peygamber'in (s.a.) irşad ve tavsiyeleri üzerine Resul-i Ekrem huzurunda; Hz. Ebu Bekr, Hz. Ali, Zübeyr, Sa'id, Enes, Hakim bin Huzzam, Amr İbn'ül-As (r.a) da Peygamber'in (s.a.) irtihalinden sonra hayırlı vakıflar yapmış sahabelerden bazılarıdır (Öztürk, 1983: 49).

\section{.İslam Ülkelerinde Vakıf}

İslamî yardımlaşma prensibinin bir sonucu olarak ortaya çıktığını gördügümüz vakıflar, Hz. Peygamber'in Medine döneminden günümüze kadar uzanan bir sürede İslam dünyasının kültürel ekonomik ve sosyal hayatında önemli roller üstlenmiş dinî ve hukukî müesseselerdir. Bu bakımdan İslam ülkelerinin tamamında, çok sayıda vakıflar ihdas edilmiştir (Kazıcı, 2003: 4146).

Emeviler zamanında vakıflar büyük bir gelişme gösterdi. Bu dönemde ilk defa yeni bazı teşebbüslerde bulunuldu. Nitekim Emevi halifesi Velid b. Abdülmelik Şam'da Ümeyye Cami için ilk defa köy ve mezraları gelir getiren birer kaynak olarak vakfetti. Emevilerden sonra gelen Abbasi devletinde vakıflar daha bir gelişme gösterdi. Bu dönemde vakıflar o derece önemli bir müessese haline geldiler ki bunların yönetimi için "Vakıflar Nezareti" adında bütün vakıfları kontrol edebilen belli bir statüye bağlanmasını sağlayan bir teşkilat kuruldu (Kazıc1, 2003: 45-46). Büyük Selçuklu Devleti'nin kurulmasıyla vakıf müessesesinin bir kat daha geliştiği görülmektedir. Selçuklular zamanında vakıf müesseselerine verilen bu önemden sonra İslam dünyasının hemen her yerinde sultanlar, vezirler, beyler, hatunlar ve varliklı kişiler medrese açma hususunda birbirleriyle yarışmaya başladılar. Büyük Selçuklulardan sonra medrese kurma faaliyetleri durmaksızın devam etti (Uzunçarş1l1, 1970: 10). 
Osmanlı döneminde, devletin siyasî ve ekonomik gücüne paralel olarak gelişip artan vakıfların ilk kurucusu Sultan Orhan Gazi'dir. Orhan Gazi, İznik’te ilk Osmanlı medresesini kurarak Osmanlı'da vakıf müessesesini devam ettirmiştir (Uzunçarş111, 1941: 281). Osmanlı ülkesinin dört bir yanında mescitler, medreseler, mektepler, ribatlar, tekkeler, türbeler, köprüler, sulama kanalları, hastaneler, kervansaraylar, imâretler, kütüphaneler, hamamlar vs. gibi birçok dinî-hayrî tesis, hep vakıflar sayesinde insanlığın hizmetine sunulmuştur. $\mathrm{Bu}$ vakıf geleneği devletin yıkılışına kadar çeşitlenerek varlığını sürdürmüştür (Köprülü, 1942: 12).

\section{Vakfin Kuruluşu İçin Aranan Şartlar}

Dinî ve hukukî bir müessese olan vakıf işleminin meydana gelebilmesi için gerek vakfı tesis eden vâkıfta, gerekse vakfedilen malda bazı şartların bulunması gerekmektedir. Bilhassa vakfın ihdasında belirtilen ifadeler oldukça büyük önem arz etmektedir. Zira bu ifadeler, vakfin rüknünden sayılmaktadırlar. Bunlar: "Malımı vakfettim", "Malımı habs ettim, tasadduk ettim" veya "Sadaka-i müebbede ile sadaka ettim" gibi sözlerdir. Vakfın kuruluşu ile ilgili şartlar; vakıfta aranan şartlar ve vakf edilen malda aranan şartlar olmak üzere iki kısımda ele alınmalıdır (Kazıcı, 2003: 42-46):

\section{a. Vakıfta (Vakfeden) Bulunması Gereken Şartlar}

1- Vakıfın, temlik ve teberrua ehil olması gerekir. Temlike ehliyet, kendi malını bir başkasına bedel veya bedelsiz olarak (satabilme) edebilme ehliyetidir. Teberrua ehliyet ise, bir şahsın kendi mülkünü ve hakkını karşılıksız olarak temlik veya sskat edebilmesi ve muamelenin hukuken geçerli sayılmasıdır.

2- Vâkıf, borcundan dolayı mahcur olmamalıdır.

3- Vâkıfın, vakfa rızası bulunmalıdır. Bu bakımdan, hangi şekilde olursa olsun zorlama sonucu yapılan vakıf, sahih değildir. Zira vakfın sıhhati, rızaya bağlıdır.

4- $\quad$ Vâkıf, vakfettiği mülkü, inancına göre hayır ve sevap kazanmak niyeti ile yapmış olmalıdır. Zira vakıfta gözetilen gaye, Allah'ın rızası ve toplumun menfaatidir. Vakfin nihai hedefi de Allah'ın rızasıdır (Kazıc1, 2003: 42-44).

\section{b. Vakfedilen Malda Bulunması Gereken Şartlar}

1. Vakfedilen mal, vakıf esnasında vâkıfın mülkü olmalıdır. Zira bir şahıs, başkasının mülkünde vakıf suretiyle bir tasarrufta bulunamaz.

2. Vakfedilen mal deyn (alacak) veya menfaat olmamalıdır. Bu bakımdan bir kimse, başkasından alacağını vakfedemez. 
3. Vakf olunacak malın akâr olması gerekir. Akâr, ev, daire, dükkan, ağaç ve arazi gibi gelir getiren taşınmaz (gayr-1 menkul) mülk olmalıdır.

4. Vakfedilecek mal, malum ve muayyen olmalıdır. Vakfa konu teşkil eden malın, sonradan meydana gelebilecek anlaşmalıkları önleyecek kadar bilinmesi ve belirli olması gerekir.

5. Vakfedilecek bina ve ağaçlar müstahikku'l-lal' (yıkılmaya veya sökülmeye mahkum) olmamalıdır.

6. Vakıfta muhayyerlik olmaz. Mesela bir kimse belli bir zaman içinde vakfı yapma veya yapmama hususunda muhayyer olmak üzere bir malı vakf etse bu vakıf sahih bir vakıf olamaz.

7. Vakıf, gelecekteki bir duruma bağlı olmamalıdır. Başka bir ifade ile vakıf müncez olmalıdır. Sözgelimi, bir kimse "şu işim olur" veya "şu hastalıktan kurtulursam şu mülküm vakıf olsun" dedikten sonra arzusu yerine gelse bile, yaptığı vakıf sahih bir vakıf olmaz. Zira vakfin kurulması, gelecekte meydana gelebilecek olay ve kazançlara bağlanamaz.

8. Vakfın ebedî olması şarttır. Vakfın, hedef ve gayesi bakımından bunun devamlı olması gerekir. Belirli bir süre ile kayıtlı bulunan vakıflar, hukukî bakımdan sahih bir vakıf olamaz.

9. Vakfın meşrutun lehi (vakıftan yararlanacak olanlar) belli olmalıdır.

Tarihî bir müessese olarak ele alınan vakıfların tesisi ve hukukîlik kazanması, hem vakfı kuran, hem de vakfedilen malda bazı şartların bulunması ile mümkündür. Binaenaleyh bu şartlardan birinin eksik veya hiç olmaması, sahih bir vakfin oluşumu için engel sayılmaktadır. (Kazıcı, 2003: 44-46).

Vakfın kuruluş şekilleri de çeşitlilik arz eder ki üç farklı kuruluş dikkatimizi çekmektedir:

Tescil Suretiyle: Vâkıf, kadıya (hakim, yargıç) müracaat edip bir vakıf kurmak isteğini bildirir. Bunun üzerine kad1, yaptığ 1 araştırmada müsbet bir sonuç elde ederse o zaman şahitlerin huzurunda ve onların da karara iştiraki ile, vakfın kurulduğunu karara bağlayıp tescil eder (kayda geçer).

Vasiyet Etmek Suretiyle: Vakıf yapmak isteyen kimsenin, ölmeden önce vasiyet etmesi suretiyle kurulan vakıftır. Şayet vakfın mirasçıları yoksa bütün mal varlığının tamamı, varsa üçte birini vasiyet etmek suretiyle vakf edebilir.

Fiil ve Hareketle: Bir kimse mülkü olan bir arsa üzerine cami inşa ettirip, ezan okutturup halkın, camide cemaatla namaz kılmasına izin verir, 
kendisi de bu cemaatin içinde yer alırsa bu cami, "vakf-1 lazım" suretiyle vakıf olur (Kazıc1, 2003: 47-48).

\section{Vakfın İdaresi}

Nezaret kavramı kelime anlamı itibari ile, bir şeye basiretle bakıp tetkik etmek ve düşünmek manalarını ifade eder. Hukuk termolojisinde ise iki anlamı mevcuttur; velâyet ve tevliyetin eş anlamlısı olarak bunların ifade ettiği manaları ifade eder. Bu anlamda vakfın nazırı, vakfı idare eden mütevellinin vakıf hakkındaki tasarruflarını kontrol eden ve vakıf işlerinde mütevellinin görüşüne müracaat mecburiyetinde bulunduğu görevliye denir (Akgündüz, 1988: 276).

Bir vakfın mütevellisi mevcut iken hiç kimse o vakfın tasarruflarına karışamaz. Ancak mütevellilerin tasarrufları belli makam ve kişilerce teftiş ve kontrol edilir. Bu teftiş ve kontrol işini yani nezaret görevini yürüten iki organ vardır:

Birincisi; bir vakfı kuran vâkıf, vakfına mütevelli tayin ettiği gibi, onun tasarruflarını kontrol edecek bir nâzır da tayin edebilir. Hem nâzır hem de mütevellisi olan vakıflarda, nâzırın re'yi alınmadıkça, mütevelli vakıf üzerinde tasarrufta bulunamaz. Nezâret görevi de diğer vakıf görevleri gibi vâkıfın tayini veya hâkimin tevcihi ile elde edilir.

İkincisi; bilindiği gibi yarg1 erkine sahip olan hakimlerin, bütün vatandaşlar ve mallar üzerinde olduğu gibi, vakfın malları üzerinde de velâyet-i ammeden gelen bir kontrol ve teftiş yetkileri vardır. Hatta vakıf mütevellileri, ayrı bir nâzırı bulunsa da, bazı tasarrufları yapabilmek için, velâyet-i amme sahibi olan hâkimlerin reylerini almak mecburiyetindedir. İşte hâkimlere tanınan bu umumi teftiş ve murakebe yetkisi de nezâret adı ile adlandırılmaktadır (Akgündüz, 1988: 276-277).

Devletin velâyet-i âmmesini kullanarak vakıfları kontrol etmek demek olan nezâret görevini üstlenen evkâf teşkilâtı, tarihin muhtelif devirlerinde ve hususen Osmanlı Devleti'nin son zamanlarında, birçok vakıfların (özellikle mazbut vakıfların) bizzat idaresi demek olan tevliyet görevini de üstlenmişlerdir. Böylelikle evkâf teşkilâtları, hem nezaret hem de tevliyet görevlerini kendilerinde toplamışlardır (Akgündüz, 1988: 277).

Vakfiye

Vakfiye veya vakıf-name, vâkıfın vakfın teşekkülü ve işleyişi hususunda tanzim ettiği hüküm ve kaideleri ve bunların kadı tarafından tescilini ihtiva eden hukukî bir nizamnâme (yönetmelik) dir. Bu vakfiyeler, kağıt ve parşömen 
tomarlara, veya hacmi bir ilâ dört yüz sayfa arasında değişen defterlere yazılmıştır (Yediyıldız 2003: 4; Sümer 1977: 15). Vakfiyeler, Allah'a hamd ve senâ, Resûlullah'a salât ve selâm ile başlar (Gökbilgin, 1977: 20). Bu başlangıçtan sonra vakfiyelerde, insanlara yardım ile hayrı teşvik edici, âyet ve hadisler bulunur. Vakfiyelerde umumiyetle şu hususlar yer alır (Kazıcı, 2003: 50-51):

1. Vakf olunan malların neler olduğu,

2. Vakf olunan bu malların nasıl idare edileceği,

3. Vakıf gelirlerinin nerelere ve kimlere sarf edileceği,

4. Vakfın, kimler tarafından yönetileceği, müesseselerde kaç kişinin çalışacağ bunlara ne kadar ücret ödeneceği, bu ücretlerin hangi gelirlerden elde edileceği, eşyanın fiyatı vs. gibi konular teferruatı bir şekilde açıklanır.

5. Kadının, vakfın sıhhat ve lüzumuna dair olan hükmü yer alır.

6. Sonunda da tarih ve şuhûdu'l-halin mühürleri ve üst kısmında kadının mührü yer alır (Kazıc1, 2003: 51).

İslam tarihinde ilk vakfiyenin, Hz. Ömer tarafindan yazıldığı söylenmekle birlikte, Hz. Peygamber devrinde mi yoksa Hz Ömer'in halifeliği zamanında mı olduğuna dair kesin bir bilgiye henüz sahip değiliz. Büyük bir ihtimal bunun, Hz. Ömer'in kendi hilâfeti zamanında olmasıdır.

Sosyal hayatımıza dinamizim kazandıran, toplumsal yardımlaşma ve birleşmeye vesile olan hayırlı işler yapma noktasında insanlarımızı teşvik eden vakıf kültürümüze örnek bir vakfa ait vakfiye ${ }^{8}$ şu şekilde tanzim edilmiştir:

\section{"Bağışlayan ve esirgeyen Tanrı adıyla"}

Övgü, âlemlerin Rabbi olan Allah'a özgüdür. Mizan durdukça salât ve selam da sürekli olarak öncekilerle sonrakilerin efendisi ve yıldızların önderi Peygamber Efendimiz Hz. Muhammed'e, onun insanların teşvikçileri ve inananların önderleri olan yakınları ile arkadaşlarına olsun...

$\mathrm{Bu}$ vakıf satılamaz, rehin olarak verilemez, miras olarak alınamaz.

Hicret y1lının 772 Şabanı (Şubat-Mart, 1371)

Duruma tanik olanlar:

\footnotetext{
${ }^{8}$ Vakfiyeler ile ilgili daha detaylı bilgi için bkz: Fuat Köprülü, "Vakıf müessesesi ve vakıf vesikalarının tarihî ehemmiyeti", Vakıflar Dergisi, Sayı: I, Ankara 1938, s. 1-6; İbrahim Ateş, "Vakfiyelerde Duâ ve Bedduâlar", Vakıflar Dergisi, Sayı: XVIII, Anakara 1983, s. 5-54; Ziyâeddin Efendi, Câmi'-i envâru's-sukûk ve lâmi' 'z-Ziyâ lizevi's-sükûk, İstanbul 1284, s. $184 \mathrm{vd.}$
} 
Buna tanık oldu: Bu satırları yazan

Buna tanık oldu: Cemşid Ağa

Buna tanık oldu: Sülüce Bolad

Ve burada bulunan başkaları...(Çağatay, 1978: 12)

Örnek bir başka vakfiye de şu şekilde düzenlenmiştir: "Vakfedilen Alan Köyü'nün gelirinden aşçıya yılda 4, ekmekçiye 4, onarımcıya 4 ve nazıra yine 4 mud (1 mud: $100-120 \mathrm{~kg}$ ) buğday verilmektedir. Vakfiyede tedris ciheti için 40, yardımcılar için 10 mud buğday tahsis edilmiştir (Kayaoğlu, 2000: 52). Görüldüğü gibi vakfiyeler en ince teferruata kadar açıklama içeren bir resmi belge hüviyeti taşımaktadır.

Vakıf müesseselerinin bu şümullü hizmetleri umumiyetle altı kısımda mütalâa edilebilir :

1- Vâkıfın (vakıf tesis yapanın) servet ve parasının beyhude ve fuzuli yerlere sarfına mâni olmak

2- Fakr-u zarurette olanlara iktisadi, mali, içtimai yardım sağlamak.

3- Bütçesiyle âmme hizmetlerini tam manasıyla göremeyen devletlere âmme hizmetlerinin görülmesinde ve şümulünde ferdî mâmelekenin ${ }^{9}$ iştirâki suretiyle yardım etmek.

4- Milletin dinî ihtiyaçlarını âyin ve ibadet arzularını tatmin ve bu uğurda yapılan âbideler dolayısıyla, milletin tarihini ve turistik imkanlarını zenginleştirmek.

5- Millî servetin daimî surette işletilmesi ile muattal kalmasına engel olmak.

6- Millî Eğitim sahasında rol almak (Berkli, 1965: 85).

\section{SONUÇ}

Vakıf, insanla beraber mevcut olan karşılıklı dayanışma ve başkalarına iyilik yapma duygusunu, hukukî statüye kavuşturan ve ona süreklilik kavramını sağlayan, tüzelkişiliğe sahip hukukî ve sosyal bir müessesedir. Vakıflar, devamlılık vasfını haiz ve sağlam bir hukukî yapıya sahip olma özelliğini, İslam ile kazanmıştır. Vakıfların İslam toplumuna sunduğu hayrî ve sosyal hizmetlerin bir sonucu, hukukî kurumlaşması İslam hukukçuları tarafından tedvin edilmiş ve ona hükmî şahsiyet tanınmıştır (Öztürk, 1983: 152).

Vakiflar, toplumsal huzursuzlukların giderilmesi ve toplumda sosyal refahın sağlanması, kültürel bozuklukların giderilmesi, ekonomik dengenin

\footnotetext{
9"Bir şahsın hayır konusunda varını yoğunu ortaya koyması" anlamına gelmektedir.
} 
sağlanması, kısaca toplum düzeninin oluşturulm,asında önemli bir görev ifa eden müesseselerimizdendir. Vakıflar, toplum içindeki dayanışmanın arttırılması, aile ve toplum içinde kuşaklar arasındaki bağların kuvvetlendirilmesi açısından önemli bir görev üstlenmiştir. İşte bu yolla, halkın ibadeti için camiler; eğitimi için medrese ve mektepler; okumak ve bilgi ve görgüyü arttırmak için kütüphaneler; hastalara şifa bulmak için dar'üşşifalar, hastaneler; akıl hastaları için bimarhaneler; açları doyurmak amacıyla imarethaneler; ticari temin için bedestenler, arastalar; susuzluğu gidermek ve temizlenmek için, suyolları-şadırvanlar-sebiller-hamamlar; kervancılar için kervansaraylar; yolcular için hanlar-tabhaneler; saati öğrenmek ve takip etmek için muvakkithaneler; ulaşım için köprüler inşa ederek yerleşik düzene geçmişler ve şehirleşmeyi tamamlamışlar, bu eserlerin devamlı ayakta kalması için de gelir getirici mülkler bırakılmış, personel atamaları yapılmış; dolayısıyla birçok kişiye iş imkanı ve devamlılık temin edilmiştir (Akbulut, 2007: 72). Ayrıca vakıfların ülke ticaretine ve ekonomik hayatın gelişmesine önemli tesirleri olmuştur. Vakıflar, büyük sanat eserlerinin, hat, taş, ağaç, maden işçiliği, tezhip, çini, kitap cilt, ebru gibi sanat dallarının gelişmesine, şaheserler verilmesine katkıda bulunmuşlardır. Vakfiyelerin dil, kültür, tarih, hukuk, iktisat, sosyoloji hatta folklor açısından da önemi bulunmaktadır.

Temelinde Allah rizasi, hayır duygusu, insanlık ve yurt sevgisi yatan vakıfların gelişmesinin başlıca sebeplerinden biri de İslam dininin hayri ve içtimai hizmetlere verdiği önemdir. Hz. Muhammed zamanından itibaren Müslümanlar arasında adeta bir yarışma hamlesi ile kurulmuş olan vakıflar, Türk-İslam toplumunda büyük ilerleme kaydederek, yüzy1llarca milletimizin ortak yardımlaşma duygularına tercüman olmuştur. Bugün bile bütün canlılığ1 ve haşmeti ile varlığını sürdüren vakıflar, toplumun ihtiyaçlarıyla birlikte hizmet alanlarını arttırarak yaşatmaktadırlar. Amacı ne olursa olsun, bir vakfın çalışmaları, Allah'ın rızasına ters ve toplumun zararına olmamalıdır.

\section{KAYNAKLAR}

Akbulut, İ. (2007), "Vakıf kurumu, mahiyeti ve tarihi gelişimi", Vakıflar Dergisi, Sayı: XXX, Vakıflar Genel Müdürlüğü Yayınları, Ankara.

Akgündüz, A. (1988), İslâm Hukukunda ve Osmanlı Tatbikatında Vakıf Müessesesi, Türk Tarih Kurumu Yayınları, Ankara.

Ateş, İ. (1983), "Vakfiyelerde Duâ ve Bedduâlar", Vakıflar Dergisi, Sayı: XVIII, Ankara. 
Berkli, Ş. (1965), "Vakıfların gördüğü çeşitli hizmetler", Vakıflar Dergisi, Sayı:VI, Vakıflar Umum Müdürlüğü Neşriyatı, İstanbul.

Çağatay, N. (1978), "Sultan Murad Hüdavendigâr adına düzenlemiş bir Vakfiye", Vakıflar Dergisi, Sayı: XII, Ankara.

Develioğlu, F. (1995), Osmanlıca-Türkçe Ansiklobedik Lûgat, Aydın Kitabevi Yayınları, Ankara.

Gökbilgin, M. T. (1977), Osmanlı Müesseseleri Teşkilâtı ve Medeniyeti Tarihine Bir Bakış, İstanbul.

Kayaoğlu, İ. (2000), "Turumtey Vakfiyesi”, Vakıflar Dergisi, Sayı: XII, Ankara.

Kazıcı, Z. (2003), Osmanlı Vakıf Medeniyeti, Bilge Yayınları, İstanbul.

Köprülü, F. (1938), "Vakıf müessesesi ve vakıf vesikalarının tarihî ehemmiyeti”, Vakıflar Dergisi, Sayı: II, Ankara.

Köprülü, F. (1942), "Vakıf Müessesesinin Hukukî Mahiyeti ve Tarihî Tekâmülü” vakıf vesikalarının tarihî ehemmiyeti”, Vakıflar Dergisi, Sayı: I, Ankara.

Öztürk, N. (1983), Menşe'i ve Tarihi Gelişimi Açısından Vakıflar, Vakıflar Genel Müdürlüğü Yayınları, Ankara.

Sümer, F. (1977), "XIV Yüzyılda Türkiye”, Yüzyıllar Boyunca Türk Sanat1, Ankara.

Uzunçarş111, İ. H. (1941), “Gazi Orhan Bey Vakfiyesi” Belleten, Sayı: V/19, Ankara.

Uzunçarşı11, İ. H. (1970), Osmanlı Devleti Teşkilatına Medhal, Ankara.

Yediyıldız, B. (2003), XVIII. Yüzyılda Türkiye'de Vakıf Müesseseleri, Türk Tarih Kurumu Yayınları, Ankara.

Ziyâeddin Efendi, (1284) Câmi'-i envâru's-sukûk ve lâmi'’z-Ziyâ li-zevi’ssükûk, İstanbul. 